\title{
DESIGN OF LVAC DISTRIBUTION SYSTEM WITH PV AND CENTRALIZED BATTERY ENERGY STORAGE INTEGRATION-A CASE STUDY OF CAMBODIA
}

\author{
Vannak Vai ${ }^{1}$, Marie-Cécile Alvarez-Hérault ${ }^{2}$, Long Bun ${ }^{1}$, and Bertrand Raison ${ }^{2}$ \\ ${ }^{1}$ Department of Electrical and Energy Engineering, Institute of Technology of Cambodia (ITC), Phnom Penh, \\ Cambodia, e-mail: vannak.vai@itc.edu.kh \\ ${ }^{2}$ Univ. Grenoble Alpes, CNRS, Grenoble INP (Institute of Engineering Univ. Grenoble Alpes), G2Elab, \\ Grenoble, France, Tel : +33(0)4 768262 99, e-mail : marie-cecile.alvarez@g2elab.grenoble-inp.fr
}

Received Date: February 5, 2019; Revised Date: April 29, 2019; Acceptance Date: May 23, 2019

\begin{abstract}
This paper studies an optimal design of grid topology and integrated photovoltaic (PV) and centralized battery energy storage considering techno-economic aspect in low voltage distribution systems for urban area in Cambodia. This work aims at searching for an optimal topology including size of the battery energy storage by two different methods over the planning study of 15 years. Firstly, the shortest path algorithm (SPA) and first-fit bin-packing algorithm (FFBPA) are used to find out the topology which minimize the line and the load balancing. Secondly, mixed integer quadratically constrained programming (MIQCP) algorithms are developed to search for a topology which minimize conductor use and the load balancing improvement. Next, Genetic algorithm is developed to size the maximum PV peak power connected into LV network with respected to voltage and current constraints. Then, the size of battery energy storage procedure is established in order to eliminate the reverse power flow going on medium voltage (MV) grid and to improve the autonomous operation time of system. A discounted cost method is used to evaluate the solutions for different methods. Lastly, an urban area in Cambodia is chosen as a case study in this paper. Simulation results confirm the proposed method in this research.
\end{abstract}

Keywords: Battery energy storage, Low voltage, MIQCP, Photovoltaic, Planning, Techno-economic

\section{Introduction}

To meet the needs of citizens and society in electricity as well as global warming issue, the researchers are currently developing an innovative method and are searching for alternative energy sources by comparing to non-renewable energy and grid reinforcement [1]-[3]. Cambodia government has also encouraged a development of local production based on renewable energies in order to reduce the energy importation from neighboring countries [4]. This importation is presently about 25\% of the total generations [5] from Vietnam, Thailand and Laos. Moreover, more and more people are interesting to use small photovoltaic generation units integrated to AC low voltage (LVAC) distribution system in order to reduce energy need from grid [4]. However, these small PV units can be affected on planning in the LV distribution system due to power flows into $\mathrm{MV} / \mathrm{LV}$ substation. Furthermore, LV distribution systems are almost radial unbalanced system due to the presence of single-phase loads in systems; it is thus required to design an optimal topology in order to get lowest cost of systems.

The development of the grid for electrification has already been addressed in [6]-[9] for phase balancing to reduce power losses and to increase integration of distributed generation. Also, to deal with the problem of topology design, the authors in [10] have developed an radial 
distribution system optimization to find out a lowest investment cost with the path search algorithm. A dynamic programming method in [11] has been applied to obtain an optimal radial topology. Moreover, an optimal planning of distribution regarding topology by mean of adapted simulated annealing has been studied in [12] ; the authors proposed to minimize the upgrades of existing system necessary for expansion. However, these works almost have addressed with MV distribution as balanced system without distributed generation consideration.

The authors in [13] have considered the reduced losses in distribution systems with an optimal balanced load by using mixed integer nonlinear programming; this work has reduced the current flow and improved the unbalanced voltage factor (UVF). The mixed integer linear programming in [14], simulated annealing in [15], and mixed integer programming in [16], have been proposed to swap phase of 1-phase load for reducing power losses. However, these authors have investigated on load balancing of existing radial topology.

Various researchers have already dealt with LV design as isolated systems. The hybrid system of diesel-PV-battery with control has been examined in [17] and optimal size of generations [18] to provide the electricity for stand-alone system. The authors [19] have studied the development tool of isolated PV system integrated with battery and diesel generation by focusing on techno-economic aspect for Mekong countries. Also, the technical and economic analysis of hybrid PV/diesel/battery charging station for remote village has been investigated in [20]. However, these authors have focused only on isolated LV system as solar home system.

With these reasons, it is mandatory to develop an innovative method with small local production integration into the two different LV distribution topology compared to the traditional topology which presently used in Cambodia based on techno-economic considerations. This paper will only focus on as distribution system operation (DSO) aspect, the DOS will search for the PV location and sizing as well as the investment cost. This paper proposes a design of LVAC distribution as micro-grid (MG) integrating PV and battery energy storage to challenge the current electrification issues in Cambodia. In this paper, an optimal radial topology will be proposed by using mixed integer quadratically constrained programming (MIQCP) in ILOGCPLEX, shortest-path algorithm and first-fit bin-packing algorithm. Next, the penetration of PV power will be maximized so as to avoid overvoltage problem. A centralized battery energy storage will be installed at the MV/LV transformer so as to eliminate reverse power flows which may occur leading to potential overloading of the MV system. This LVAC design could be isolated from the main grid at some times of year, enabling a reduction in the investment in the MV system.

\section{Methodology}

This method purposes to search for the optimal topology including dimensioning of the PV and battery energy storage while satisfying the constraints of bus voltage and the constraints of current circulating in lines. In practice, the topology of LV system depends on the line right-ofway and the households' location, however the system performance will be improved with the proposed method. In this paper, the following three objectives will be achieved sequentially: 1) an optimal radial topology using both methods, 2) a maximization of the PV penetration and 3) an optimal size of battery energy storage. Figure 1 shows a flowchart illustrating the different steps of the proposed method. The 15 years of planning study with an annual growth rate of 3\% will be proposed. We then find the size of single-phase PV units which are connected in the network at the level of the households' nodes. Next, the battery energy storage is sized to solve 
a problem of reverse power flow and also to increase the autonomous operation time of the LVAC grid to relieve the MV system. The comparative study of the both strategies is evaluated by computing the discounted cost in the last part.

\section{Mixed Integer Quadratically Constrained Programming}

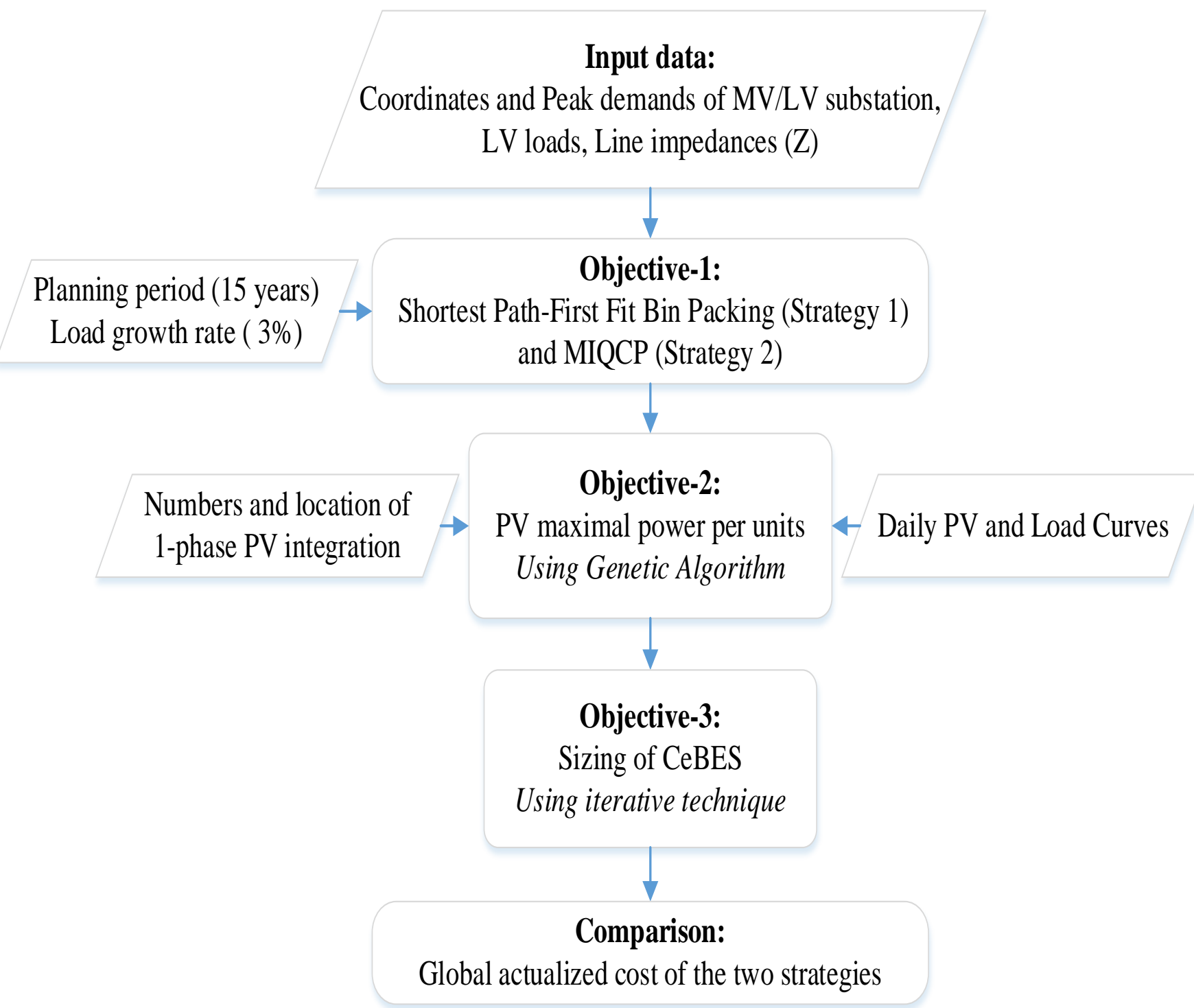

Figure 1. Flowchart of the proposed method

A graph in [21] is used as an electrical grid which is well defined as a pair of sets $G \equiv G(V, E)$, where $V=\{1.2 \ldots N\}$ is a set of $\mathrm{N}$ nodes of the graph representing the households and $\left.E \subseteq V \times V=\left\{e_{m n}\right\}(m, n) \in V\right\},\left\{e_{i j}\right\}$ is a set of segments between nodes $m$ and $n$ representing the lines of the grid. Also, a topological graph representing the grid is shown in Figure 2. 


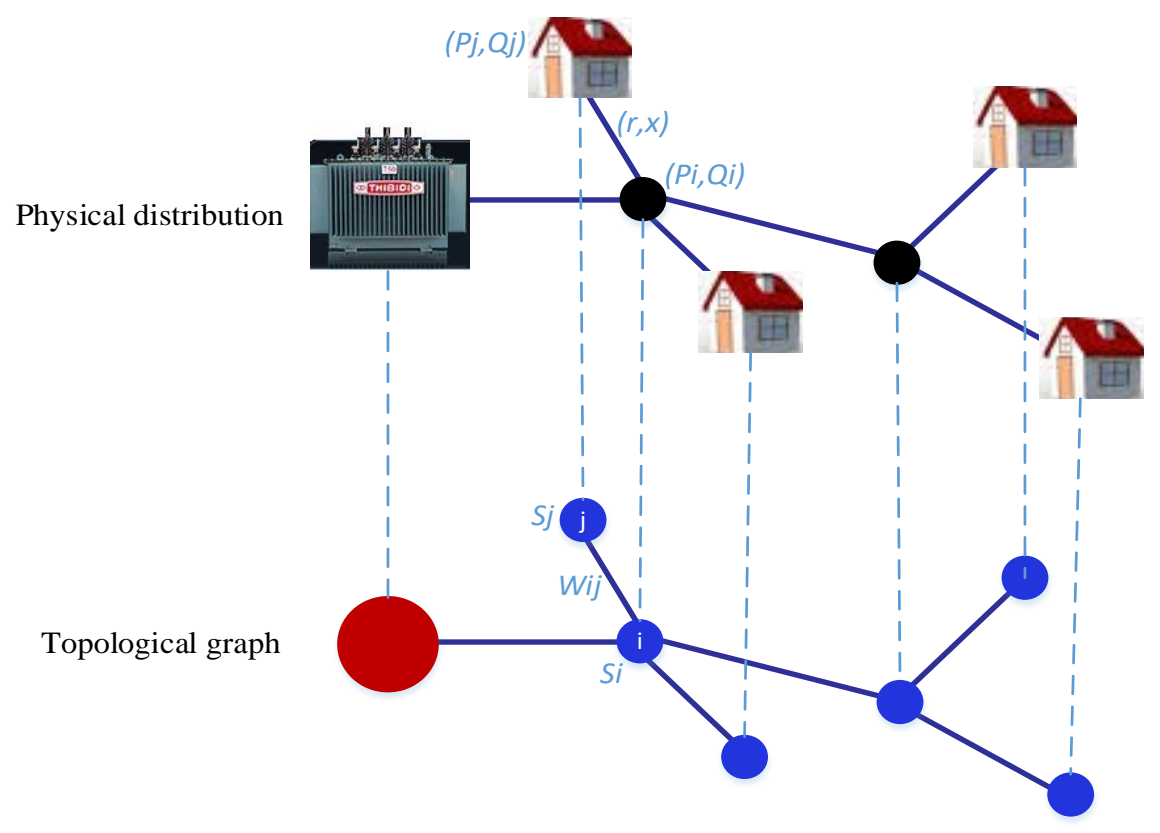

Figure 2. A graph representation of grid

The problem of optimization is to minimize conductor by MIQCP model as follows:

$$
\text { Minimize: } \sum_{(m, n) \in E} d_{m n} \cdot\left(z_{m n}+z_{p h_{-} m n}^{A}+z_{p h_{-} m n}^{B}+z_{p h_{-} m n}^{C}\right)
$$

Where:

$Z_{m n}, Z_{p h_{-} m n}^{A}, Z_{p h_{-} m n}^{B}, Z_{p h_{-} m n}^{C} \in\{1,0\}:$ connection state between two nodes $m$ and $n$ $A-B-C$ : connection phases of network

(1: node $m$ and node $n$ are linked and 0: node $i$ and node $j$ are not linked) $d_{m n} \in\left\{\mathfrak{R}^{+}\right\}, \forall(m, n) \in E$ : distance between two nodes

Subject to constraints as follows:

- $\quad$ Arborescence flow

$$
\begin{aligned}
& \sum_{(m, n) \in \delta^{i n}(n)} Z_{m n}=1, \forall n \in V \backslash S, S \text { is source } \\
& \delta^{i n}(n) \text { : set of incomming edge for } n^{\text {th }} \text { vertex } \\
& Z_{m n}+Z_{n m} \leq 1, \forall(m, n) \in E \\
& z_{p h_{-} m n}^{A} \leq Z_{n m}, \forall(m, n) \in E \\
& Z_{p h_{-} m n}^{B} \leq Z_{n m}, \forall(m, n) \in E \\
& Z_{p h_{-} m n}^{C} \leq Z_{n m}, \forall(m, n) \in E
\end{aligned}
$$


- $\quad$ Balancing of load

er $\in\left\{\mathfrak{R}^{+}\right\}$, different power between two connected phases

$p_{i}$ : active power of loads $i$

load_ $p h_{m}^{\alpha} \in\{1,0\}$ : connected phase of loads $m, \alpha=A, B$ or $C$

$$
\begin{aligned}
& \left(\sum_{m=1}^{n} p_{m} \text { load }-p h_{m}^{A}-\sum_{m=1}^{n} p_{m} \text { load }-p h_{m}^{B}\right)^{2} \leq e r^{2} \\
& \left(\sum_{m=1}^{n} p_{m} l o a d_{-} p h_{m}^{A}-\sum_{m=1}^{n} p_{m} l o a d_{-} p h_{m}^{C}\right)^{2} \leq e r^{2} \\
& \left(\sum_{m=1}^{n} p_{m} \text { load }-p h_{m}^{B}-\sum_{m=1}^{n} p_{m} \text { load }-p h_{m}^{C}\right)^{2} \leq e r^{2}
\end{aligned}
$$

- $\quad$ Allocation of load

$$
\begin{aligned}
& \forall m \in V \backslash S, S \text { is source } \\
& \text { load_ph } h_{m}^{\alpha} \in\{1,0\} \text { : connected phase of loads } m, \alpha=A, B \text { or } C \\
& \text { load }{ }_{-} p h_{m}^{A}+\text { load }_{-} p h_{m}^{B}+\text { load }_{-} p h_{m}^{C}=\left\{\begin{array}{l}
1, \text { if } 1 \text { phase } \\
3, \text { if } 3 \text { phase }
\end{array}\right.
\end{aligned}
$$

- $\quad$ Line capacity limit

$\forall(m, n) \in E:$

$P_{m n}, p_{m n}^{\max }$ : active power circulating and maximum active power circulating in line $r$ $Q_{m n}, q_{m n}^{\max }$ : reactive power circulating and maximum reactive power circulating in li $P_{m n}^{A} \leq p_{m n}^{\max } z_{p h_{-} m n}^{A}, P_{m n}^{B} \leq p_{m n}^{\max } z_{p h_{-} m n}^{B}, P_{m n}^{C} \leq p_{m n}^{\max } z_{p h_{-} m n}^{C}$ $Q_{m n}^{A} \leq q_{m n}^{\max } z_{p h_{-} m n}^{A}, Q_{m n}^{B} \leq q_{m n}^{\max } z_{p h_{-} m n}^{B}, Q_{m n}^{C} \leq q_{m n}^{\max } z_{p h_{-} m n}^{C}$

- $\quad$ Load flow neglecting loss

$\forall m \in V \backslash S, S$ is source

$p_{m}$ : active power of $m$ load

$q_{m}$ : reactive power of $m$ load

load_ $p h_{m}^{\alpha} \in\{1,0\}$ : phase connected phase of $m$ load, $\alpha=A, B$ or $C$

$$
\begin{aligned}
& \sum_{(n, m) \in E} P_{n m}^{\alpha}-\sum_{(m, n) \in E} P_{m n}^{\alpha}=\left\{\begin{array}{l}
p_{m} \text { load }-p h_{m}^{\alpha}, \text { if } m \text { linked to } 1 \text { phase } \\
\frac{p_{m} \text { load }-p h_{m}^{\alpha}}{3}, \text { if } m \text { linked to } 3 \text { phases }
\end{array}\right. \\
& \sum_{(n, m) \in E} Q_{n m}^{\alpha}-\sum_{(m, n) \in E} Q_{m n}^{\alpha}=\left\{\begin{array}{c}
q_{m} \text { load }-p h_{m}^{\alpha}, \text { if } m \text { linked to } 1 \text { phase } \\
\frac{q_{m} \text { load }}{3} p h_{m}^{\alpha} \\
3
\end{array}\right.
\end{aligned}
$$




\section{Shortest Path Algorithm (SPA) and First-Fit Bin-Packing Algorithm (FFBPA)}

The LVAC system in Cambodia consists of single-phase or three-phase LV feeders going from a three-phase MV/LV substation to several single-phase poles. Each customer is connected to the energy meter at pole or wall. The optimal topology is designed by ensuring the minimization of the conductor length and the load balancing improvement. For this purpose, the SPA and FFBPA are used to find a topology. In the graph theory, the SPA problem consists in searching a path between two nodes in a graph so that the sum of length of lines of its segments is minimized. The FFBPA problem consists in storing all items into a well-defined number of bins, while minimizing the different total weight of each bin. In this paper, the items are the load demands $\left(\mathrm{P}_{\mathrm{L}}, \mathrm{Q}_{\mathrm{L}}\right)$ and the bins are the ABC phases of the grid, respectively. Firstly, the SPA is run to search for the closest electrical pole's node to connect the household, and then the FFBPA is used to equilibrium the phases of those connected households. Figure 3 and Figure 4 show the pseudocode of the shortest path-first fit bin packing applied to this paper.

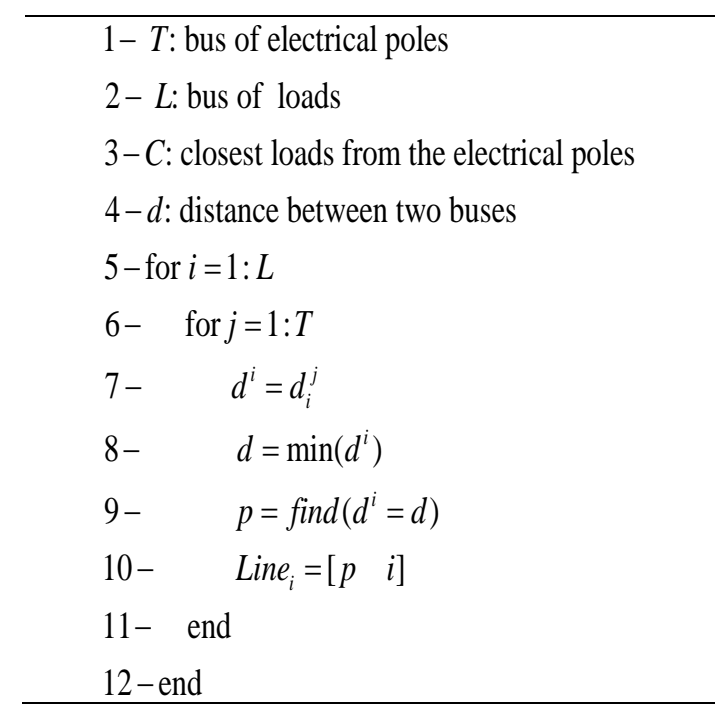

Figure 3. Shortest path pseudocode

\begin{tabular}{|c|c|}
\hline $1-T:$ bus of electrical poles & $15-\quad \operatorname{elseif}\left(\operatorname{sum}\left(P_{i-1}^{A}\right)==\operatorname{sum}\left(P_{i-1}^{C}\right) \& \operatorname{sum}\left(P_{i-1}^{A}\right)<\operatorname{sum}\left(P_{i-1}^{B}\right)\right)$ \\
\hline $2-P_{T}^{\alpha}$ : load demand at electrical pole T, $\alpha=\mathrm{A}$, B or C & $16-\quad \mathrm{ph}=[1,0]$ \\
\hline $3-\mathrm{y}_{T}^{\alpha}$ : phase connection at electrical pole T, $\alpha=\mathrm{A}$, B or C & idx = randperm (numel(ph)) \\
\hline $4-$ for $i=1: T$ & {$\left[\mathrm{y}_{i}^{A}, y_{i}^{B}, y_{i}^{C}\right]=[\mathrm{ph}(\mathrm{idx}(1)), 0, \mathrm{ph}(\mathrm{idx}(2))]$} \\
\hline $5-\quad$ if $\left(\operatorname{sum}\left(P_{i-1}^{A}\right)<\operatorname{sum}\left(P_{i-1}^{B}\right) \& \operatorname{sum}\left(P_{i-1}^{A}\right)<\operatorname{sum}\left(P_{i-1}^{C}\right)\right)$ & 19- elseif $\left(\operatorname{sum}\left(P_{i-1}^{B}\right)==\operatorname{sum}\left(P_{i-1}^{C}\right) \& \operatorname{sum}\left(P_{i-1}^{B}\right)<\operatorname{sum}\left(P_{i-1}^{A}\right)\right)$ \\
\hline$\left[\mathrm{y}_{i}^{A}, y_{i}^{B}, y_{i}^{C}\right]=[1,0,0]$ & $\mathrm{ph}=[1,0]$ \\
\hline elseif $\left(\operatorname{sum}\left(P_{i-1}^{B}\right)<\operatorname{sum}\left(P_{i-1}^{A}\right) \& \operatorname{sum}\left(P_{i-1}^{B}\right)<\operatorname{sum}\left(P_{i-1}^{C}\right)\right)$ & idx = randperm (numel(ph)) \\
\hline $8-\quad\left[y_{i}^{A}, y_{i}^{B}, y_{i}^{C}\right]=[0,1,0]$ & {$\left[\mathrm{y}_{i}^{A}, y_{i}^{B}, y_{i}^{C}\right]=[0, \mathrm{ph}(\mathrm{idx})]$} \\
\hline $9-\quad$ elseif $\left(\operatorname{sum}\left(P_{i-1}^{C}\right)<\operatorname{sum}\left(P_{i-1}^{A}\right) \& \operatorname{sum}\left(P_{i-1}^{C}\right)<\operatorname{sum}\left(P_{i-1}^{B}\right)\right)$ & $23-$ \\
\hline$\left[\mathrm{y}_{i}^{A}, y_{i}^{B}, y_{i}^{C}\right]=[0,0,1]$ & $\mathrm{ph}=[1,0,0]$ \\
\hline elseif $\left(\operatorname{sum}\left(P_{i-1}^{A}\right)==\operatorname{sum}\left(P_{i-1}^{B}\right) \& \operatorname{sum}\left(P_{i-1}^{A}\right)<\operatorname{sum}\left(P_{i-1}^{C}\right)\right)$ & idx = randperm (numel(ph)) \\
\hline $\mathrm{ph}=[1,0]$ & {$\left[\mathrm{y}_{i}^{A}, y_{i}^{B}, y_{i}^{C}\right]=\operatorname{ph}(\mathrm{idx})$} \\
\hline idx = randperm (numel(ph)) & $27-\quad$ end \\
\hline$\left[\mathrm{y}_{i}^{A}, y_{i}^{B}, y_{i}^{C}\right]=[\mathrm{ph}(\mathrm{idx}), 0]$ & 28 - end \\
\hline
\end{tabular}

Figure 4. First fit bin packing pseudocode 


\section{Maximum PV Peak Penetration}

In this paper, the distribution system operator (DSO) chooses the location of the PV. The infrastructure of electrical system is expensive and its cost depends on the power flows, among other things. So if the production is located as close as possible to the consumption, the power flows will be reduced and the costs too. Thus, it is assumed that the DSO will choose to add PV where the consumption is high. The objective is to search for the maximum PV peak power that can be connected into the network. The maximal power of PV units is solved by using Genetic Algorithm(GA) with unbalanced load flow [22] given in Equation 7. Firstly, we insert the system data and the daily PV-load curve. Then, the maximal PV peak power is defined using GA: the peak power of the PV is constrained with voltage limit ( $\mathrm{V}_{\max }=1.06 \mathrm{pu}$, voltage regulation in Cambodia) [23] and the maximal current limit where PVs are connected are reached for each hour over day. The maximal power of each hour are kept and finally the maximum PV penetration is the minimum of these PV powers. The objective function is given by:

$$
\text { Maximize: } \quad\left[P e a k P V_{i}^{A}(t), \operatorname{PeakPV}_{j}^{B}(t), \operatorname{PeakPV}_{k}^{C}(t)\right]
$$

Where:

$$
\operatorname{PeakPV}_{i, j, k}^{A, B, C}(t) \in\left\{\mathfrak{R}^{+}\right\}, \forall(i, j, k) \in \text { bus }
$$

PeakPV $V_{i, j, k}^{A, B, C}(t)$ : PV peak power of A,B,C phase for $i, j, k$ bus

Subject to:

- Voltage constraints

$$
0.95 p u \leq V_{m} \leq 1.06 p u
$$

- $\quad$ Current constraint

$$
I_{m} \leq I_{\max }
$$

\section{Battery Energy Storage Integration}

The purpose of the battery energy storage is for charging the energy during the moments where reversed power occurs from low voltage (LV) network to medium voltage (MV) network, and for discharging for the duration of the network has to provide the LV consumers, providing that the state of charge (SoC) of the battery keeps between minimum and maximum of state of charge (i.e. SoC $\min$ and $\mathrm{SoC}_{\max }$ ). The power measured at $\mathrm{MV} / \mathrm{LV}$ transformer is taken, and in case its value is positive, the battery energy storage will be discharged in case the SoC of the battery storage rests in allowable range, and if its value is non-positive, the battery storage will be charged. In addition, the primary source is the battery and the secondary source is the MV network, if available. For every hour of time step of the year, this battery energy storage charge and discharge powers are calculated to suppress the reverse power at the MV/LV transformer. Moreover, the size of the battery energy storage is affected by load demand, PV production and system topology. 


\section{Cost Computation}

The method of discounted cost is used in this paper to assess the different proposed strategies over $N$ planning years. The capital expenditure (CAPEX) and operational expenditure (OPEX) for energy losses of LV grid has been taken into account in this method.The discounted cost [22] is formulated by:

$$
D_{\text {total }}=\sum_{t=0}^{N} \frac{C_{i n v}(t)+C \times E N_{\text {main }}(t)}{(1+d)^{t}}
$$

Where:

$-\mathrm{D}_{\text {total }}$ : total actualized cost in kUSD

$-\mathrm{C}_{\text {inv }}(t)$ : investment cost in the year $\mathrm{t}$ in kUSD

$-\mathrm{C}$ : electricity cost in $\mathrm{kUSD} / \mathrm{kWh}$

$-E N_{\text {main }}(t)$ : energy from main grid in the year $t$ in $\mathrm{kUSD}$

$-\mathrm{d}$ : discount rate in \%

\section{Case Study: A Village in Cambodia}

\section{Case Study Description}

The village located in Veal Sbov, Cambodia has been selected as a case study for this work. The system supplies from the $1^{\text {st }}$ bus to $45^{\text {th }}$ bus with $22 / 0.4 \mathrm{kV}$ substation. The active power ( $\mathrm{P}_{\text {active }}$ ) of test system is about $200 \mathrm{~kW}$ in totally with power factor of $0.95 \mathrm{pf}$ at the initial year, these values are provided by normal distribution for each energy meter with $5 \mathrm{~kW}$ mean and $0.5 \mathrm{~kW}$ standard deviation due to unavailable information in that village presently. The village is illustrated in Figure 5.

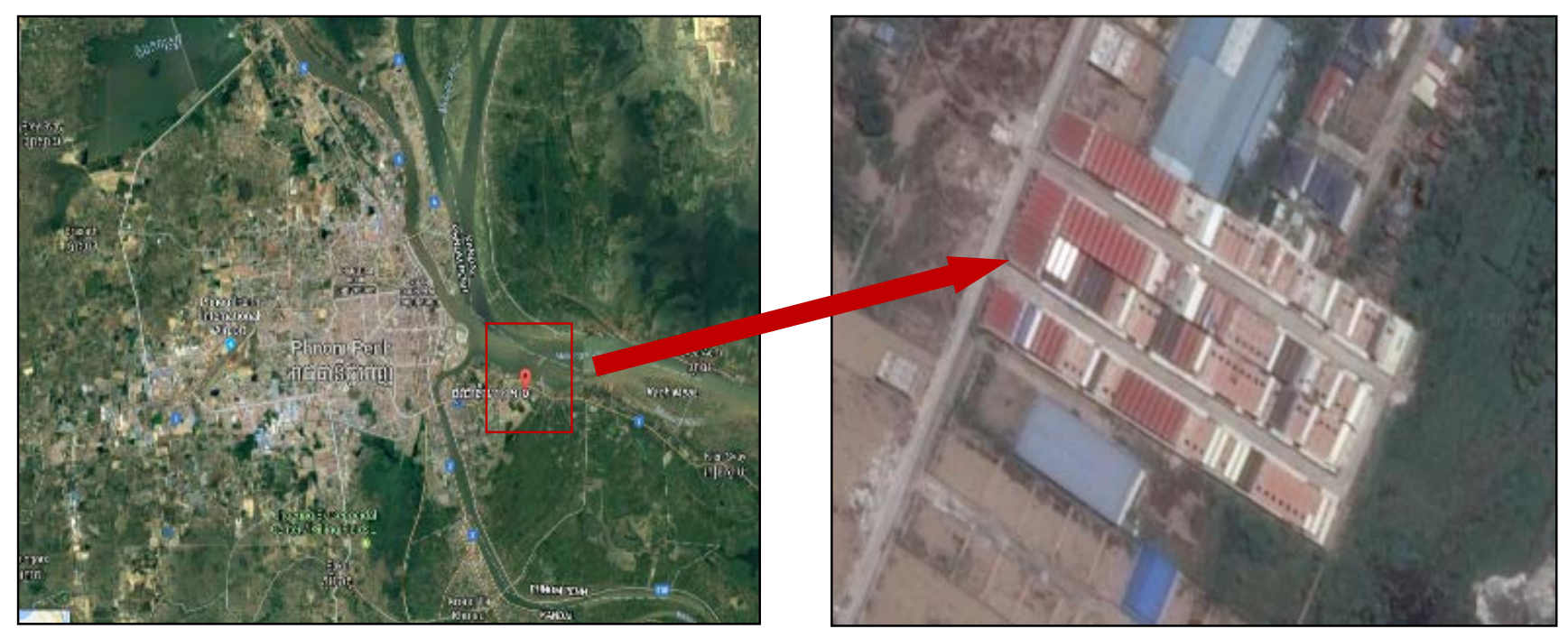

Figure 5. Site study in Veal Sbov Village, Phnom Penh [1132'04” N, 10458'06” E] 


\section{Input Parameters}

Some inputs parameters are required so as to confirm the proposed method and are listed in Table 1. The planning study is 15 years. With this primary study, one single-phase PV units per feeder and 4 PV units in total have been chosen; this is about 10\% of total households. A 3\% growth rate has been chosen, which is high since Cambodia is a developing country; load profiles are built based on real measurements. Moreover, as real data of solar radiation are presently not available, NASA [24] data have been selected in this study.

\section{Table 1. Input Parameters}

\section{Data}

$$
\begin{aligned}
& \text { Planning study } \\
& \text { Load growth } \\
& \text { Load curve } \\
& \text { PV curve } \\
& \text { Number of PV }
\end{aligned}
$$

\section{Case Study}

15 years

$3 \%$ [22]

Local measurement

NASA

4 units

A normalized daily load curve taken from local measurements and a PV curve taken from NASA are given in Figure 6. The normalized load curve is simulated repeatedly for oneyear simulation in this article. This supposition is realistic since the customers do not use electric heaters, so the electrical devices are used in the same way during the year. Moreover, if the airconditiner are presented in the system, the power consumption is increased, the energy used will be supplied by the grid.
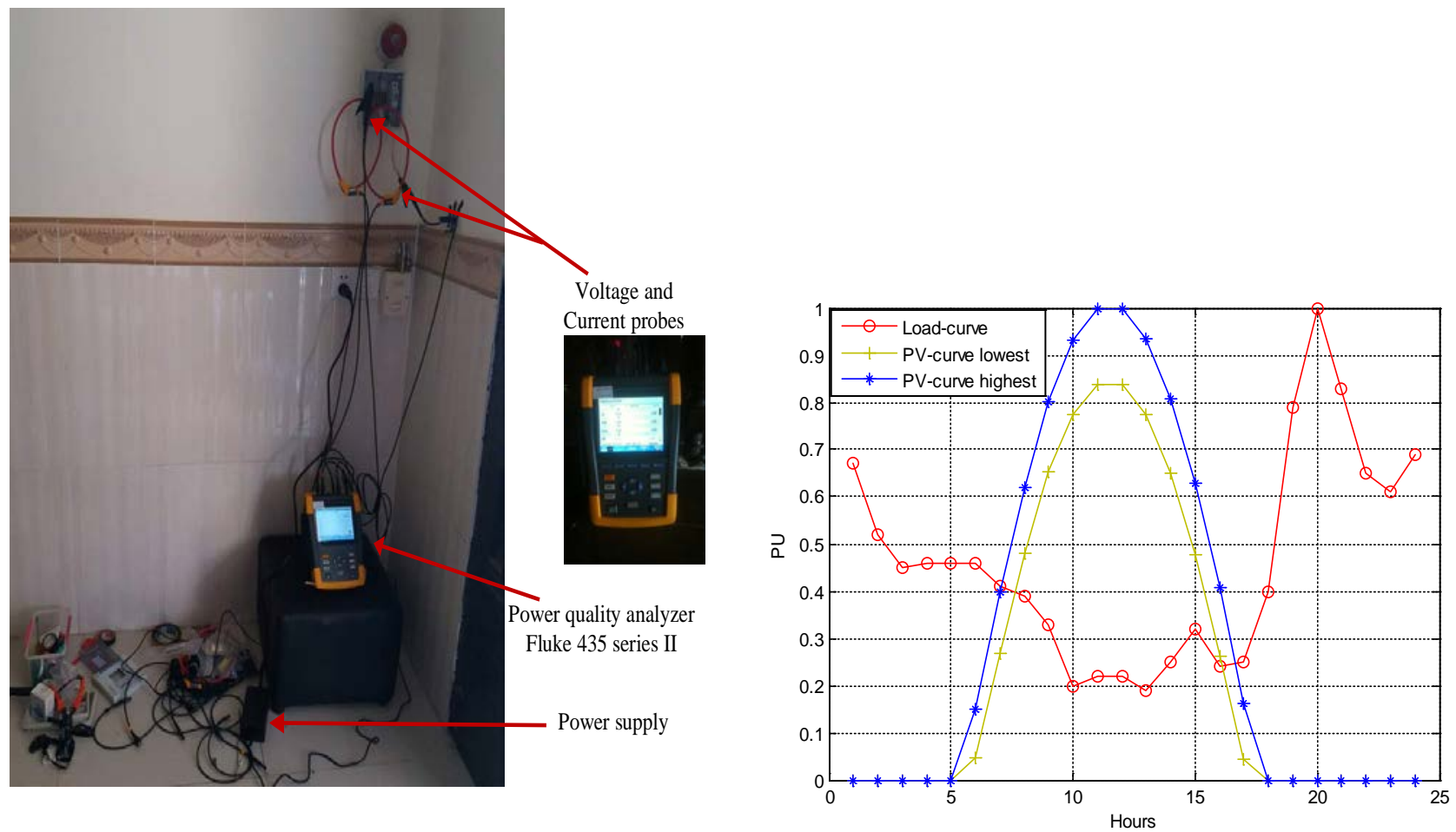

Figure 6. Measurement of load curve using power quality analyzer (Top) and normalized daily PV and load curves (Bottom) 
In addition to the above, the setting taken for the analysis of economic are given in Table 2. They consist of the cost of the electricity, cables, PV-BES as well as inverters.

Table 2. Economic Parameters

Parameters

Actualization rate

Electricity cost

ABC-4x70 mm² cable cost

PV panel cost

$\mathrm{PV}$ inverter cost

Battery energy storage cost

Bi-directional inverter cost
Value

$12 \%[22]$

$0.2 \mathrm{USD} / \mathrm{kWh}[5]$

$4 \mathrm{kUSD} / \mathrm{km}[22]$

$1.2 \mathrm{kUSD} / \mathrm{kWp}[25]$

$0.72 \mathrm{kUSD} / \mathrm{kW}[25]$

$0.13 \mathrm{kUSD} / \mathrm{kWh}[19]$

$1.155 \mathrm{kUSD} / \mathrm{kW}[19]$

\section{Simulation Results and Discussions}

\section{Optimal Radial Topology}

The optimal radial topologies of two different strategies are performed by using the SPA-FFBPA and MIQCP algorithms as shown in Figure 7 and Figure 8. The difference of shape and color in the figure illustrate the different phase connection of the households in LV system.

In both cases, there are four feeders supplied the customers. For $1^{\text {st }}$ strategy (S1), all the main lines are three-phase whereas in $2^{\text {nd }}$ strategy (S2), main lines are single and two-phase. The reason is that S2 purposes to minimize the conductor use including load balancing improvement but S1 aims at optimizing only the load balancing. Moreover, a classical conductor size of $70 \mathrm{~mm}^{2}\left(\mathrm{I}_{\max }=185 \mathrm{~A}\right.$ ) is used for all main lines and $16 \mathrm{~mm}^{2}\left(\mathrm{I}_{\max }=66 \mathrm{~A}\right)$ from the main lines to each energy meter which is currently Cambodian standard.

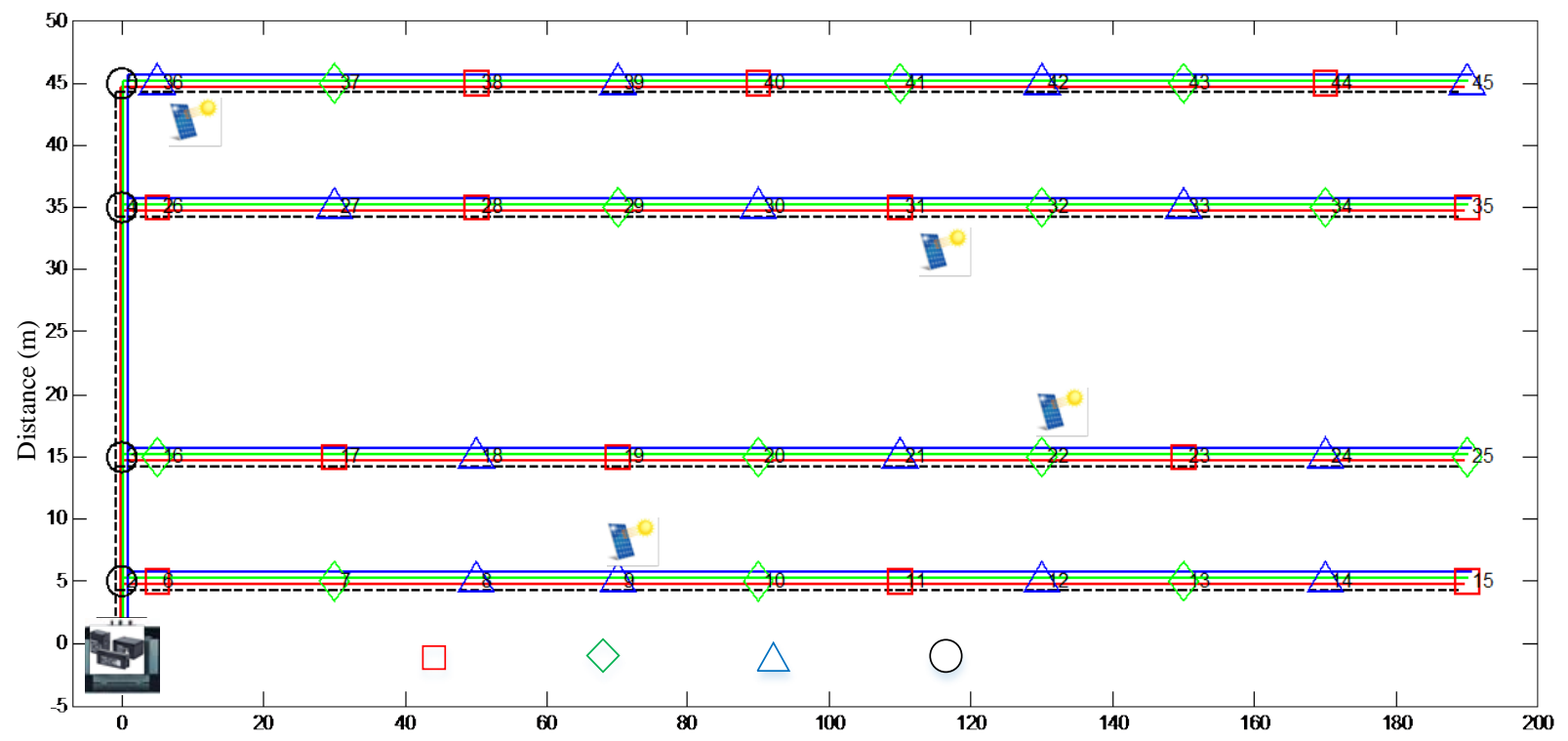

Figure 7. Optimal radial topology by using shortest path-first fit bin packing algorithm (S1) with PV-battery energy storage 


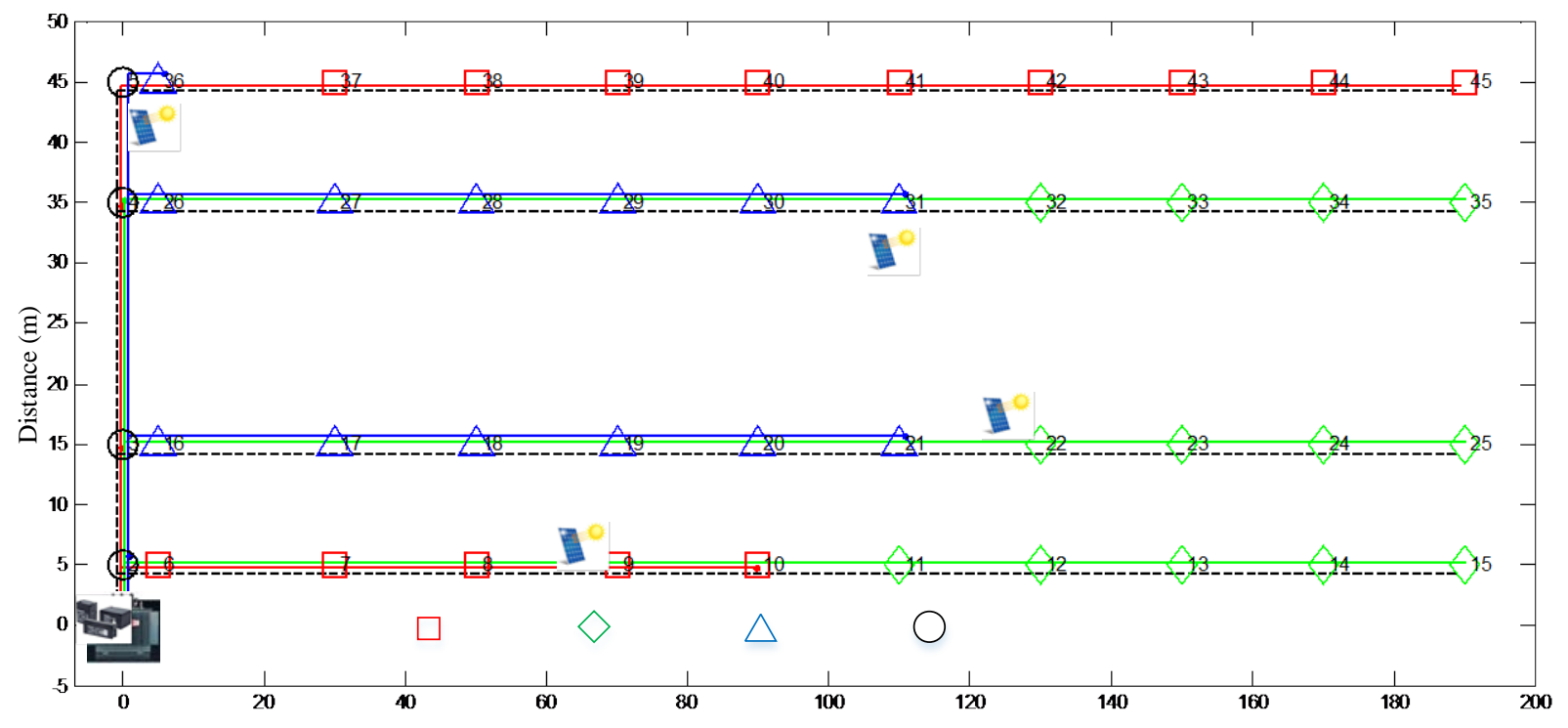

Figure 8. Optimal radial topology by using MIQCP algorithm (S2) with PV-battery energy storage

Additionally, the voltage profile during the peak load of two different SPA-FFBPA and MIQCP are shown in Figure 9. It can be noticed that the voltage drop of MIQCP is higher than SPA-FFBPA but both algorithms are remained within the limit (i.e. $\mathrm{V}_{\mathrm{m}}=0.9 \mathrm{pu}$ ) at the end of planning.
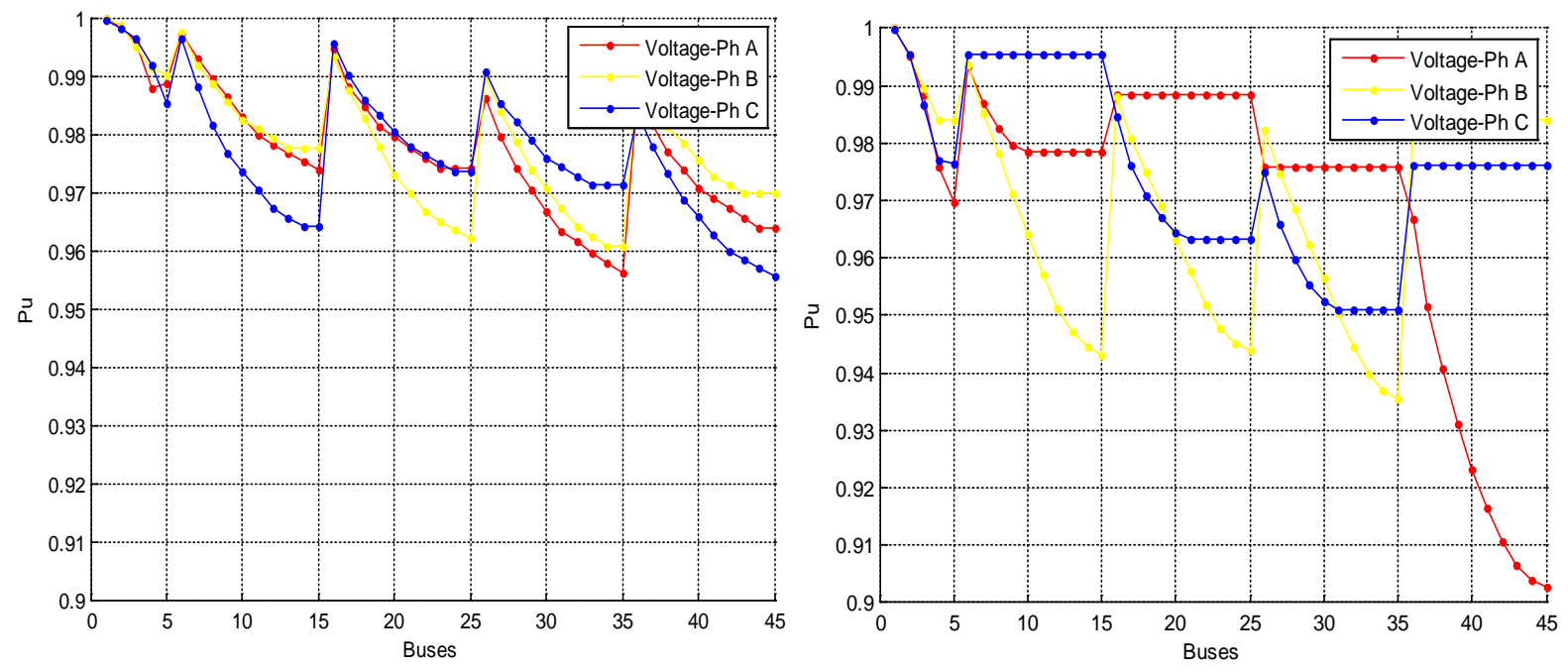

Figure 9. Voltage profile at peak load by different strategy for year 15 (s1-left, s2-right)

\section{Maximum PV Peak Power}

The size of four 1-phase PV units that are connected into the network are listed in Table 3. It can be noticed that the peak power of all the 1-phase PVs are not much difference in the whole network and the PV penetration is about $32 \%$ of $200 \mathrm{~kW}$ in totally. In order to compare, S1 and $\mathrm{S} 2$, the PV peak power scenarios found for S1 will be implemented to S2. 
Table 3. Maximum PV Peak Power Main Lines Connected PV Maximum PV PV Penetration

$1^{\text {st }}$ feeder $9^{\text {th }}$ bus

$2^{\text {nd }}$ feeder $22^{\text {nd }}$ bus

$15.90 \mathrm{kWp}$

$3^{\text {rd }}$ feeder

$31^{\text {st }}$ bus

$15.86 \mathrm{kWp}$

$4^{\text {th }}$ feeder

$36^{\text {th }}$ bus

$15.85 \mathrm{kWp}$

$31.76 \%$

$15.91 \mathrm{kWp}$

\section{Sizing of Battery Energy Storage}

According to the strategy described in section of battery energy storage integration, we have obtained the battery storage sizing of $88 \mathrm{kWh}$ (S1)-87 kWh (S2) with a bi-directional inverter of $36 \mathrm{~kW}$. As the result, the network is worked as an isolated micro-grid with an autonomy of $27 \%$ for the initial planning year and $0 \%$ at the end of planning due to impact of load growth.

Furthermore, Figure 10 provides the histogram of the annual active power at the $\mathrm{MV} / \mathrm{LV}$ transformer in case without/with integrated PV-battery energy storage at the initial year of S1. It can be noticed that there is reverse power follow due to power production from PV (see figure 10-top-right), however this power has been removed completely from the network by storing these amount to battery energy storage (see Figure 10-bottom). Also, this reverse power flow is mostly impacted by load consumption, PV production and the system topology. Regarding to the battery operation, the SoC at the beginning of a day is equal to the SoC at the end of a day.
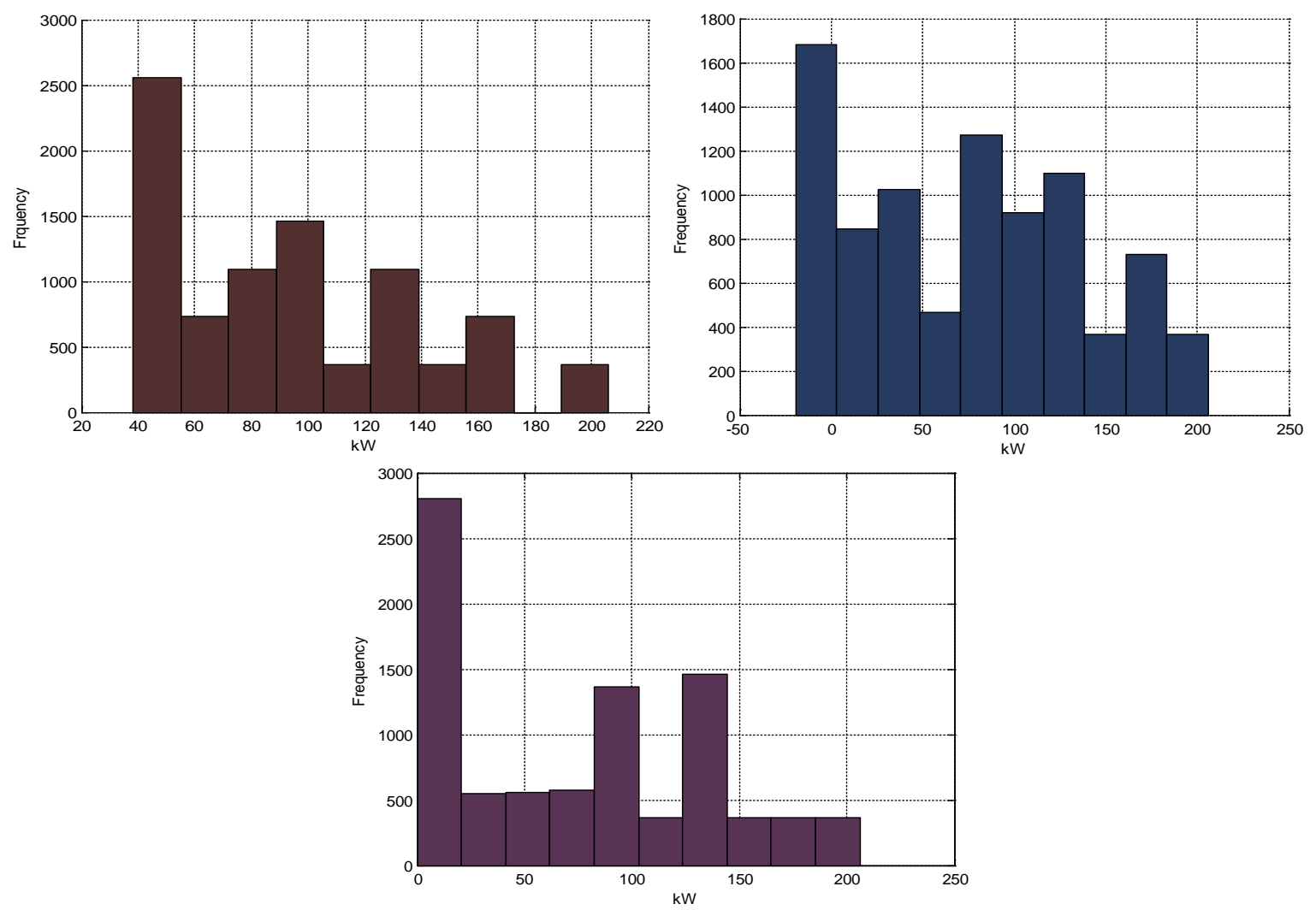

Figure 10. Histogram of the annual active power at the MV/LV without PV-battery (top-left), with PV (top-right), with PV-battery (bottom) 


\section{Indicators}

The integration of PV-battery energy storage makes it possible to reduce the energy used from 820 MWh (S1)/840 MWh (S2) to 653 MWh (S1)/675 MWh (S2), representing about $20 \%$ reduction as shown in Table 4 . Furthermore, the autonomous operation is increased from $0 \%$ to $27 \%$; it is autonomous $1 / 4$ the time when it can be operated as an isolated LV system freely from the main grid.

Table 4. Simulation Results of the Grid in Initial Year

\begin{tabular}{cccc} 
Parameters & $\begin{array}{c}\text { Without PV-Battery } \\
\text { (S1 / S2) }\end{array}$ & With PV (S1 / S2) & $\begin{array}{c}\text { With PV-Battery } \\
\text { (S1 / S2) }\end{array}$ \\
\hline Active power [kW] & $206.14 / 216.48$ & $206.14 / 216.48$ & $206.14 / 216.48$ \\
Energy used [MWh] & $818.98 / 841.38$ & $673.81 / 695.20$ & $653.13 / 674.97$ \\
Autonomous[\%/Year] & $0 / 0$ & $16.67 / 16.67$ & $26.69 / 26.54$ \\
PV penetration [\%] & $0 / 0$ & $31.76 / 31.76$ & $31.76 / 31.76$ \\
\hline
\end{tabular}

\section{Comparison Between Shortest Path-First Fit Bin Packing and MIQCP}

The discounted cost is calculated to compare the different proposed algorithms. The initial cost of the proposed algorithms in both without and with PV-battery integration are provided in Table 5 and Table 6. Due to having no available information presently about construction cost of LV network, this discounted cost is considered only a conductor cost, distributed generations cost and cost of the energy use so as to confirm the proposed algorithms.

\section{Table 5. Initial Cost without PV-Battery Integration}

Proposed Algorithm Without PV-Battery

\begin{tabular}{|c|c|c|c|c|}
\hline \multirow[t]{2}{*}{ Items } & \multicolumn{2}{|c|}{$\begin{array}{c}\text { Strategy 1: Shortest Path-First Fit } \\
\text { Bin Packing }\end{array}$} & \multicolumn{2}{|c|}{ Strategy 2: MIQCP } \\
\hline & Quantity & Cost & Quantity & Cost \\
\hline $70 \mathrm{~mm}^{2}$ cable & $3440 \mathrm{~m}$ & $3.440 \mathrm{kUSD}$ & $2005 \mathrm{~m}$ & 2.005 kUSD \\
\hline Energy from main & 818.98 MWh & 147.416 kUSD & 841.38 MWh & $151.448 \mathrm{kUSD}$ \\
\hline Total cost (kUSD) & \multicolumn{2}{|c|}{150.856} & \multicolumn{2}{|c|}{153.453} \\
\hline
\end{tabular}

Table 6. Initial Cost with PV-Battery Integration

Proposed Algorithm With PV-Battery

\begin{tabular}{ccccc}
\multirow{2}{*}{ Items } & \multicolumn{2}{c}{$\begin{array}{c}\text { Strategy 1: Shortest path-First Fit } \\
\text { Bin Packing }\end{array}$} & \multicolumn{2}{c}{ Strategy 2: MIQCP } \\
\cline { 2 - 5 } & Quantity & Cost & Quantity & Cost \\
\cline { 2 - 5 } & $3440 \mathrm{~m}$ & $3.440 \mathrm{kUSD}$ & $2005 \mathrm{~m}$ & $2.005 \mathrm{kUSD}$ \\
Energy from main & $653.13 \mathrm{MWh}$ & $117.563 \mathrm{kUSD}$ & $674.97 \mathrm{MWh}$ & $121.495 \mathrm{kUSD}$ \\
PV & $63.52 \mathrm{kWp}$ & $76.224 \mathrm{kUSD}$ & $63.52 \mathrm{kWp}$ & $76.224 \mathrm{kUSD}$ \\
Battery & $88.37 \mathrm{kWh}$ & $11.488 \mathrm{kUSD}$ & $86.80 \mathrm{kWh}$ & $11.284 \mathrm{kUSD}$ \\
PV inverter & $4 * 16 \mathrm{~kW}$ & $46.08 \mathrm{kUSD}$ & $4 * 16 \mathrm{~kW}$ & $46.08 \mathrm{kUSD}$ \\
Battery inverter & $36 \mathrm{~kW}$ & $41.58 \mathrm{kUSD}$ & $36 \mathrm{~kW}$ & $41.58 \mathrm{kUSD}$ \\
Total cost (kUSD) & \multicolumn{2}{c}{296.375} & \multicolumn{2}{c}{298.668} \\
\hline
\end{tabular}


As seen in Table 6, it can be noticed that S1 and S2 are not much difference in terms of cost. For the initial year, the cost of case with PV-battery energy storage integration is two times higher comparing to the case without PV-battery energy storage. Additionally, Figure 11 provides the global discounted cost of two different proposed algorithms. With this figure, in case of without integrated PV-battery energy storage, the total discounted cost of the S1 is 8531.29 kUSD and 8856.97 kUSD for S2. These global discounted costs have been reduced considerably in the case with PV-battery energy storage integration. In conclusion, S1 with PVbattery energy storage integration looks to be less expensive than S2 in all the cases.

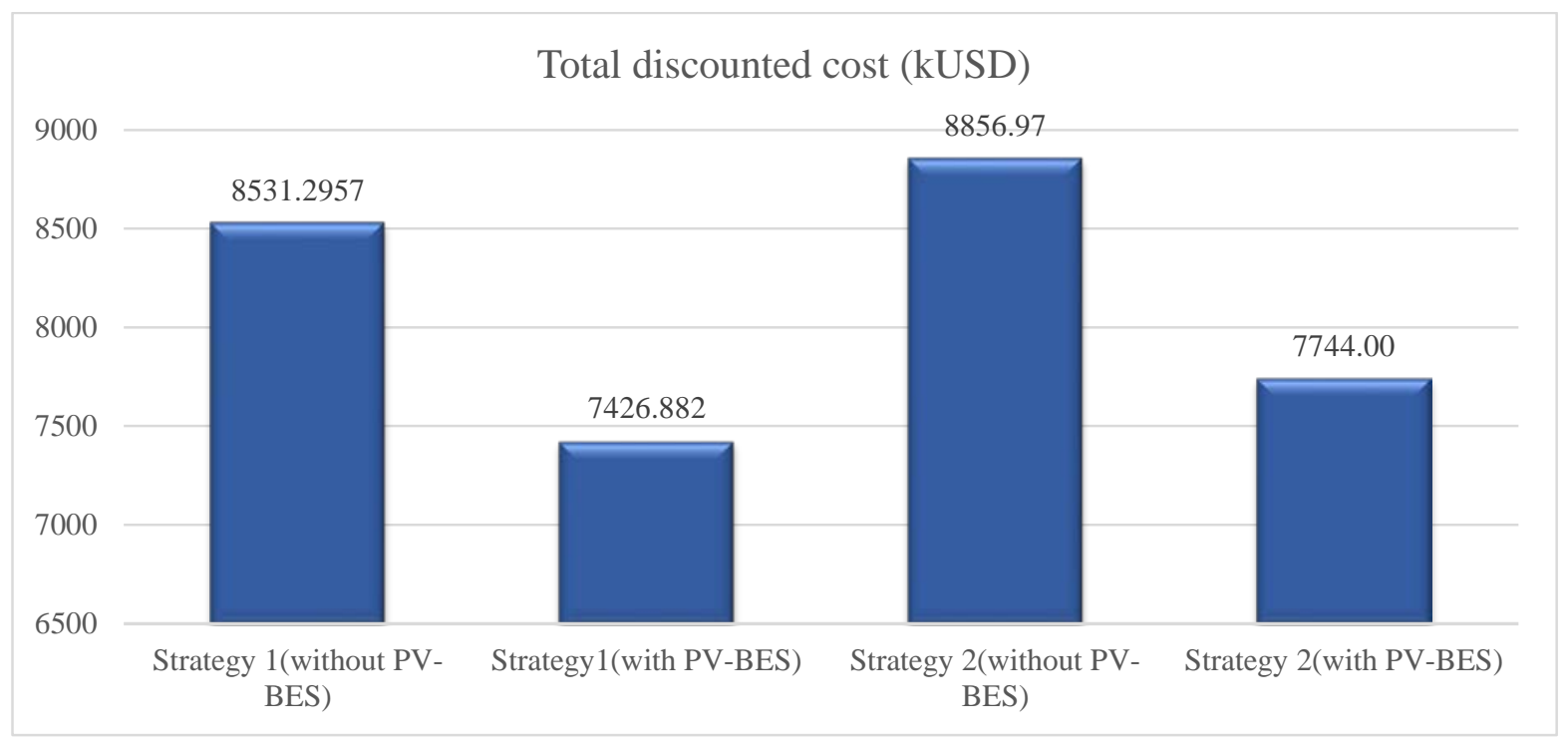

Figure 11. Global discounted cost of two different strategies (BES: Battery Energy Storage)

\section{Conclusions and Future Work}

In this paper, the optimal design of LVAC distribution system with integrated distributed generations for urban area has been studied by searching for the optimal topology and size of PV-battery storage integrated into grid over the planning study. The shortest-path, first-fit bin packing, and mixed integer quadratically constrained programming have been developed to search for the optimal topology with load balancing improvement. Moreover, the maximal PV peak power which can be connected into grid was determined while respect to voltage and current constraints. The size of battery energy storage has been determined in order to decrease the size of $\mathrm{MV} / \mathrm{LV}$ transformer and to remove the reverse power flows as well as increasing the autonomous operation of the grid. In Cambodia, the integrated PV-battery storage into LV systems would be less expensive that traditional systems in urban area. An optimization of topology as non-linear programming by taking into the power losses as an objective function will be studied in the future. As an expected result, the connected-phase of each energy meter in the system will be changed so as to minimize the power losses and it will also result in changing the indicators of the system (e.g. PV penetration, autonomous operation time, size of energy storage). However, it will be slightly different compared to the shortest-path and first fit bin packing algorithms. Moreover, the completed normalized load curve in different day, week, and month will be considered. In addition, a study for rural village and the development a model to tackle an intermittent behavior in both load and PV production will be investigated in future works. 


\section{Acknowledgment}

This work was supported by the Institute of Technology of Cambodia (GEE, ITC, Cambodia), Grenoble Electrical Engineering Laboratory (G2Elab, Grenoble INP, University of Grenoble Alpes, France) and French Government.

\section{References}

[1] G. Balaban, G.C. Lazaroiu, V. Dumbrava, and C.A. Sima, “Analysing renewable energy source impacts on power system national network code,” Inventions, Vol. 2, No. 23, pp. 117, 2017.

[2] F.C. Robert, G.S. Sisodia, and S. Gopalan, "An intelligent approach to strengthening of the rural electrical power supply using renewable energy resources,” In: Proceedings of the International Conference on Green Energy Technology, IOP Publishing Ltd, United Kingdom, pp. 1-9, 2017.

[3] H. Schermeyer, C. Vergara, and W. Fichtner, "Renewable energy curtailment: A case study on today’s and tomorrow’s congestion management,” Energy Policy, Vol. 112, No. 1, pp. 427-436, 2018.

[4] REF-DC, Program for the Development of Rural Electrification of Electricité du Cambodge (EDC) through Department of Rural Electrification Fund (REF)," REF Department, Electricité du Cambodge, Phnom Penh, Cambodia, 2017.

[5] Electricity Authority of Cambodia (EAC), Report on Power Sector of the Kingdom of Cambodia, 2018. [Online]. Available: https://eac.gov.kh/publication/report/

[6] S. Mansani, and R.Y. Udaykumay, "An optimal phase balancing technique for unbalanced three-phase secondary distribution systems,” In: 2016 IEEE $7^{\text {th }}$ Power India International Conference (PIICON), Institute of Electrical and Electronics Engineering (IEEE), Bikaner, India, pp.1-6, 2016.

[7] S. Mansani, and R.Y. Udaykumay, "Backward sweep technique based phase balancing algorithm for secondary distribution system,” In: 2017 IEEE PES Asia-Pacific Power and Energy Engineering Conference (APPEEC), Institute of Electrical and Electronics Engineering (IEEE), Bangalore, India, pp.1-6, 2017.

[8] H.A. Mostafa, "Phase balancing of a 3-phase distribution system with a considerable penetration of single phase solar generators," In: 2014 IEEE PES T\&D Conference and Exposition, Chicago, Illinois, United States, pp.1-6, 2014.

[9] M. Swapna, and S. Member, “An algorithm for optimal phase balancing of secondary distribution systems at each node,” In: 2016 IEEE PES $13^{\text {th }}$ International Conference on Transmission \& Distribution Construction, Operation \& Live-Line Maintenance (ESMO), Columbus, Ohio, United States, pp.1-6, 2016.

[10] V. Kumar, R. Krishan, and Y. Sood, "Optimization of radial distribution networks using path search algorithm,” International Journal of Electronics and Electrical Engineering, Vol. 1, No. 3, pp. 182-187, 2013.

[11] N.G. Boulaxis, S. Member, and M. Papadopoulos, "Optimal feeder routing in distribution system planning using dynamic programming technique and gis facilities," IEEE Transactions on Power Delivery, Vol. 17, No. 1, pp. 242-247, 2002.

[12] V. Gouin, M.C. Alvarez-Herault, and B. Raison, "Optimal planning of urban distribution network considering its topology,” In: $23^{\text {rd }}$ International Conference on Electricity Distribution, Cired, Lyon, France, pp. 1-5, 2015.

[13] M. Granada Echeverri, R. Gallego Rendón, and J.M. López Lezama, “Optimal phase 
balancing planning for loss reduction in distribution systems using specialized genetic algorithm,” Ingenieria y Ciencia, Vol. 8, No. 15, pp. 121-140, 2012.

[14] H.M. Khodr, I.J. Zerpa, P.M. Deoliveira-de Jesus, and M.A. Matos, "Optimal phase balancing in distribution system using mixed-integer linear programming," In: 2006 IEEE/PES Transmission \& Distribution Conference and Exposition: Latin America, IEEE, Caracas, Venezuela, pp. 1-6, 2006.

[15] J. Zhu, G. Bilbro, and M.Y. Chow, "Phase balancing using simulated annealing," IEEE Transactions on Power Systems, Vol. 14, No. 4, pp. 1508-1513, 1999.

[16] J. Zhu, M.Y. Chow, and F. Zhang, "Phase balancing using mixed-integer programming," IEEE Transactions on Power Systems, Vol. 13, No. 4, pp. 1487-1492, 1998.

[17] L.N. An, T. Quoc-Tuan, B. Seddik, and B. Nguyen, "Optimal design of an isolated photovoltaic-diesel-battery hybrid system by using an iterative algorithm," In: 2014 IEEE PES General Meeting, IEEE, National Harbor, Maryland, United States, pp. 1-6, 2014.

[18] L.N. An, T. Quoc-Tuan, and B. Seddik, "Control strategies of a hybrid PV-diesel-battery system in different operation modes,” In: 2013 IEEE Grenoble Conference PowerTech, IEEE, Grenoble, France, pp. 1-6, 2013

[19] N. Ketjoy, Photovoltaic Hybrid Systems for Rural Electrification in the Mekong Countries, Thesis (PhD), University of Kassel, Kassel, Hessen, Germany, 2005.

[20] C. Chhim, N. Ketjoy, and T. Suriwong, "Techno-economic analysis of PV battery charging station in Kampot, Cambodia,” Journal of Clean Energy Technology, Vol. 2, No. 4, pp. 369-373, 2014.

[21] M. Loebl, “Introduction to graph theory,” In Discrete Mathematics in Statistical Physics, Vieweg+Teubner, Wiesbaden, Germany, pp. 13-49, 2010.

[22] V. Vai, E. Gladkikh, M.-C. Alvarez-Herault, B. Raison, and L. Bun, "Planning of lowvoltage distribution systems with uncertainty on load demand in urban areas,” In: 2017 IEEE International Conference on Environment and Electrical Engineering and IEEE Industrial and Commercial Power Systems Europe (EEEIC / I\&CPS Europe), IEEE, Milan, Italy, pp. 1-6, 2017

[23] N.R. King, “Electric power technical standards of the Kingdom of Cambodia,” 2004. [Online]. Available: http://portal.mrcmekong.org/assets/documents/CambodianLaw/Electric-Power-Technical-Standards-(2004).pdf

[24] V. Vai, E. Gladkikh, M.-C. Alvarez-Herault, B. Raison, and L. Bun, "Study of low-voltage distribution system with integration of PV-battery energy storage for urban area in developing country," In: 2017 IEEE International Conference on Environment and Electrical Engineering and 2017 IEEE Industrial and Commercial Power Systems Europe (EEEIC / I\&CPS Europe), IEEE, milan, Italy, pp. 1-6, 2017.

[25] EcoSun, “Ecosun Solar Appliance Products,” 2017. [Online]. Available: http://ecosunproducts.webs.com/ 